\title{
Role of eNOS and TGF $\beta 1$ gene polymorphisms in the development of diabetic nephropathy in type 2 diabetic patients in South Indian population
}

\author{
Sindhu Varghese and Subbaraj Gowtham Kumar
}

\begin{abstract}
Background: Diabetic nephropathy is known to be a leading complication of diabetes mellitus, characterized by diverse aspects such as high urinary albumin level, elevated blood pressure, and genetic susceptibility leading to end-stage renal disease. The current study was carried out to investigate the association of eNOS and TGF 1 gene polymorphisms in the progression of diabetic nephropathy among type 2 diabetic patients in the South Indian population. The eNOS and TGFB1 genetic variants were genotyped in 280 T2DM patients, 140 with DN, 140 without DN, and 140 controls. Genotyping was performed using ARMS PCR and the genomic variants were confirmed by the Sanger sequencing method.

Results: A significant $(p<0.05)$ association was observed in the genotypic frequencies of eNOS (G $>$ T) polymorphism in the T2DM patients with diabetic nephropathy when compared to controls. The frequency of TT (heterozygous) genotype was observed to increase in patients with type 2 diabetes and DN when compared to the diabetic patients without DN and controls. This indicates that diabetic patients with TT genotype are at an increased risk to develop DN. However, TGF 1 ( G >C) polymorphism did not show any association in the allele and genotypic frequencies with DN when compared with T2DM and controls.

Conclusion: The results of the study propose a strong influence of TT genotype of eNOS gene be significantly linked with diabetic nephropathy in T2DM patients. Whereas no association was examined concerning TGF $\beta 1$ gene polymorphism and DN. Nevertheless, large sample size studies are required to confirm the part of these genetic variants in the development of DN.
\end{abstract}

Keywords: Diabetic nephropathy, Gene polymorphism, Microalbuminuria, eNOS, TGF $\beta 1$, Type 2 diabetes mellitus

\section{Background}

Diabetic nephropathy (DN) is recognized to be a distinct and substantial microvascular problem of both type 1 (T1DM) and type 2 diabetes mellitus (T2DM) and is a prominent source of end-stage renal disease (ESRD) [1]. DN is characterized by an early stage of

*Correspondence: gowtham_phd@yahoo.com

Faculty of Allied Health Sciences, Chettinad Hospital and Research

Institute, Chettinad Academy of Research and Education (Deemed to be

University), Kelambakkam, Tamil Nadu 603103, India microalbuminuria, deteriorating glomerular filtration rate, and hypertension that over a period of time leads to a progressive phase which ultimately drives to kidney failure, further necessitating dialysis or transplantation. Hypertension is a key factor that is known to increase the risk of DN [2]. Several factors such as high blood sugar, high blood pressure, and genetic variations might influence an individual towards DN in the immediate future [3].

The endothelial nitric oxide synthase (eNOS) gene is considered to be a promising candidate gene to 
study the predisposition of diabetic nephropathy $[4,5]$. This gene has three polymorphisms such as $894 G>T$ (rs1799983) missense mutation found in exon 7, $786 \mathrm{~T}>\mathrm{C}$ (rs2070744) polymorphism found in the promoter region and $27 \mathrm{bp}$ repeat $(4 \mathrm{~b} 4 \mathrm{a})$ found in the intron 4 region. All of these single nucleotide polymorphisms are found to be linked to the prognosis of diabetic nephropathy. The eNOS gene is proved to be one of the main factor behind endothelial dysfunction which is a hallmark of DN. The variants of the eNOS gene are proved to contribute to endothelial dysfunction as well as diminish the production of nitric oxide. The NOS3 regulation at the transcriptional, post-transcriptional and post-translational levels is known to be influenced by the genetic variants in the eNOS gene. The incidence of G894T variant causes decreased level of nitric oxide and is linked with hypertension as well. Also the genetic polymorphisms present in the eNOS gene is known to contribute in the development of endothelial dysfunction and thereby reduces the production of nitric oxide. [6] Among the polymorphisms, G894T was proved to intensify the threat of macroalbuminuria and the advancement of microalbuminuria to macroalbuminuria with a deterioration in the glomerular filtration rate as per the rise in serum creatinine levels subsequently causing diabetic nephropathy [7]. Studies have proved that the $\mathrm{T}$ allele, as well as TT genotype of eNOS 894G > T, polymorphism have a significant risk of developing DN. An increased prevalence of this polymorphism is observed among Japanese and Tunisian diabetic patients which further became the reason for renal failure [8].

Transforming growth factor-beta 1 (TGF- $\beta 1$ ) is considered as an anti-inflammatory immune negotiator that obstructs or reverses the stimulation of macrophages by interrupting with signaling by using toll-like receptor-reliant pathways [7]. TGF 1 gene comprises seven exons and is situated at the chromosome $19 q 13.1[9,10]$. Various single nucleotide polymorphisms of TGF- $\beta 1$ have been studied some among them are $869 \mathrm{~T}>\mathrm{C}$ polymorphism, where the Leucine changes to Proline in the codon 10, $-509 \mathrm{C}>\mathrm{T}$ was another SNP which was proved to be associated with a concentration of circulating TGF- $\beta 1$ protein. Another study investigated the effect of G915C polymorphism and proved its relationship with an enhanced risk of end-stage renal disease [11]. A meta-analysis study claimed that no association was observed concerning 915G > C polymorphism and diabetic nephropathy [12].

Despite all the investigations done on these two genes and their polymorphisms in the earlier case-control studies and meta-analysis studies it's still hard to come to a conclusion about the link between these genes in the progression of diabetic nephropathy.

\section{Aim}

The aim of the present investigation is to examine the association of the genetic polymorphism of eNOS (rs1799983) and TGFB1 (1800471) in diabetic patients with and without diabetic nephropathy and their risk of developing DN among the South Indian type 2 diabetic patients.

\section{Methods}

The present investigation was a prospective case-control study performed in a tertiary care hospital. The patient samples were collected and evaluated from November 2017-December 2019. During this period 280 type 2 diabetic patients with and without DN (137 men and 143 women; mean age $56.4 \pm 5.8$ years) attending the outpatient department of Nephrology and General medicine of a tertiary care center were recruited. Similarly, 140 healthy participants (60 men and 80 women; mean age $55.1 \pm 6.8$ years) were studied as a control group. The participants were dispersed into three different groups. Group A -140 type 2 diabetes mellitus patients with diabetic nephropathy, Group B- 140 type 2 diabetes mellitus patients without diabetic nephropathy, Group C- 140 healthy subjects. The clinical and demographic characteristics were obtained from all the subjects by means of a structured questionnaire and the other methodology such as, anthropometric measures, clinical examination and laboratory investigations. It included gender, age, BMI, diabetes duration, FPG, PPG, serum creatinine, HDL, LDL, VLDL, eGFR, systolic and diastolic blood pressure, smoking, and alcohol consumption. Type 2 diabetic patients were diagnosed by means of ADA criteria 2012, where the FBS level was $>126 \mathrm{mg} / \mathrm{dl}$ and PPG level was $>200 \mathrm{mg} / \mathrm{dl}$ [13]. Diabetic nephropathy patients were assessed by the level of urinary protein-to-creatinine excretion of $>30 \mathrm{mg} / \mathrm{g}$ in a $24-\mathrm{h}$ urine collection. The patients with DN were diagnosed based on the KDOQI (Kidney Disease Outcomes Quality Initiative) guidelines [14]. The participants for the study were strictly selected based on the clinical examination.

\section{Selection criteria}

The participants included for the study were male and female participants with diagnosed type 2 diabetes mellitus, subjects with age between 28 and 70 years, urinary protein-to-creatinine ratio $>30 \mathrm{mg} / \mathrm{g}$ in $24 \mathrm{~h}$ urine sample collection, albumin creatinine ratio (ACR) level between $30-299 \mathrm{mg} / \mathrm{g}$ and $\geq 300 \mathrm{mg} / \mathrm{g}$ in spot urine collection and patients with decreased eGFR levels. The participants excluded from the study were patients with 
proteinuria before the onset of diabetes, other complexities such as heart disease, urinary tract infection, and with inadequate records were left out from the study group, participants having any infectious disease and drug-induced group as well as subjects with other kidney problems. The healthy control participants were normal healthy participants in the age limit of 28-70 years old, with no history of diabetes mellitus or any other diseases.

\section{DNA isolation}

The blood samples were collected in ethylene-diamine tetra acetic acid (EDTA) anticoagulant vacutainer tubes and were stored at $-4^{\circ} \mathrm{C}$ for further isolation as well as genotyping of DNA. $5 \mathrm{ml}$ of whole blood was collected from the control and case subjects. The DNA extraction was done by using Miller's method [15]. The quality and quantity of DNA were observed with a spectrophotometer followed by agarose gel electrophoresis.

\section{Primer design and T-ARMS-PCR amplification}

The primers designed to target the two SNPs were performed by using an online software established by $\mathrm{Ye}$ et al., and accessible at http://primer1.soton.ac.uk/prime r1.html. Tetra primer-amplification refractory mutation system-PCR (T-ARMS PCR) is known to be a rapid, effective, and cost-efficient technique for the identification of mutations or SNPs [16].

\section{eNOS G894T (rs 1799983) genotyping}

The PCR product sizes for the variant rs1799983 polymorphism were as: 277 bp for two outer primers (control bands), $175 \mathrm{bp}$ for the $\mathrm{G}$ allele, and $158 \mathrm{bp}$ for the $\mathrm{T}$ allele. The PCR condition for eNOS amplification was performed in a total volume of $15 \mu \mathrm{l}$ reaction mixture containing $2 \mu \mathrm{l}$ template DNA, $2 \mu \mathrm{l}$ of each inner primers and $0.5 \mu \mathrm{l}$ of each outer primers, $5 \mu \mathrm{l}$ of PCR premix (Taq DNA Polymerase $2 \times$ Master mix RED) and $3 \mu$ of sterile water. The PCR reaction condition for the detection of the variant rs 1799983 polymorphism was $95^{\circ} \mathrm{C}$ for $2 \mathrm{~min}$ followed up by 30 cycles, in addition to denaturation at $95^{\circ} \mathrm{C}$ for $20 \mathrm{~s}$, annealing at $69^{\circ} \mathrm{C}$ for $20 \mathrm{~s}, 72^{\circ} \mathrm{C}$ for $1 \mathrm{~min}$ and a final extension at $72^{\circ} \mathrm{C}$ for $5 \mathrm{~min}$ to complete the extension of all PCR fragments. The PCR products were analyzed by electrophoresis on a $2 \%$ agarose gel, with DNA marker 100-1500 bp (Cat no: DM001-R500). Figure 1 represents the agarose gel electrophoresis result of 894G > T eNOS gene polymorphism.

\section{TGFß1 C915G (1800471) genotyping}

The PCR product sizes for the variant rs 1800471 polymorphism were as: 304 bp for two outer primers (control bands), $200 \mathrm{bp}$ for the $\mathrm{G}$ allele, and $160 \mathrm{bp}$ for the $\mathrm{C}$

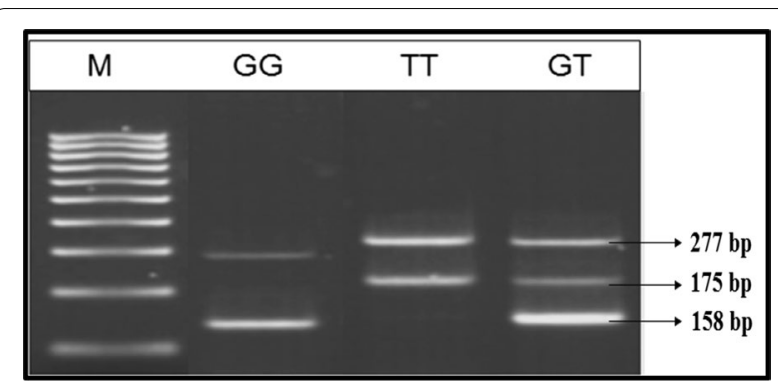

Fig. 1 Gel picture illustrating eNOS G/T polymorphism. Lane 1: DNA ladder (100 bp) Lane 2: GG genotype, Lane 3: TT genotype and Lane 4: GT genotype

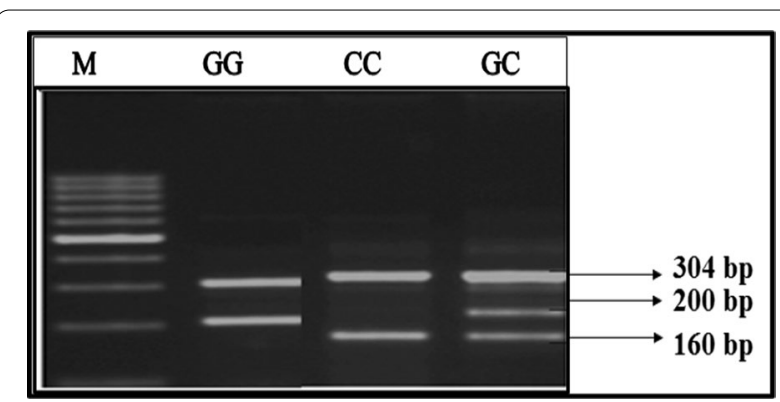

Fig. 2 Gel picture illustrating TGF $\beta 1 \mathrm{G} / \mathrm{C}$ polymorphism. Lane 1: DNA ladder (100 bp) Lane 2: GG genotype, Lane 3: CC genotype and Lane 4: GC genotype

allele. The PCR condition for TGF $\beta 1$ amplification was performed in a total volume of $15 \mu \mathrm{l}$ reaction mixture containing $2 \mu \mathrm{l}$ template DNA, $2 \mu \mathrm{l}$ of each inner primers and $0.5 \mu \mathrm{l}$ of each outer primers, $5 \mu \mathrm{l}$ of PCR premix (Taq DNA Polymerase $2 \times$ Master mix RED) and $3 \mu \mathrm{l}$ of sterile water. The reaction condition was set as follows: number of cycles 35 , initial denaturation $\left(95^{\circ} \mathrm{C}\right.$ for $2 \mathrm{~min})$, denaturation $\left(95^{\circ} \mathrm{C}\right.$ for $\left.20 \mathrm{~s}\right)$, annealing temperatures $\left(66^{\circ} \mathrm{C}\right.$ and $68^{\circ} \mathrm{C}$ for $\left.1 \mathrm{~min}\right)$, elongation $\left(72^{\circ} \mathrm{C}\right.$ for $50 \mathrm{~s}$ ) and final elongation at $72^{\circ} \mathrm{C}$ for $5 \mathrm{~min}$. The bands of amplified products were identified at three different types of genotypes were attained and observed as bands among which $304 \mathrm{bp}$ and $200 \mathrm{bp}$ for homozygous wild type, $304 \mathrm{bp}$ and $160 \mathrm{bp}$ for homozygous mutant and $304 \mathrm{bp}, 200 \mathrm{bp}$, and $160 \mathrm{bp}$ for heterozygous mutant. The PCR products were analyzed by electrophoresis on a $2 \%$ agarose gel with DNA marker $100-1500$ bp (Cat no: DM001-R500). Figure 2 shows the gel electrophoretic results for $915 \mathrm{G}>\mathrm{C}$ TGF $\beta 1$ gene polymorphism. The primers used for amplification of eNOS $(894 \mathrm{G}>\mathrm{T})$ and TGF- $\beta 1$ ( 915 G $>$ C) are listed in Table 1 . The table shows the primers designed to target the selected gene polymorphism for the T-Arms PCR. 
Table 1 Designed primer sequences used in tetra arms PCR genotyping

\begin{tabular}{|c|c|c|c|}
\hline Gene polymorphism & Primer sequence $\left(5^{\prime}-3^{\prime}\right)$ & Melting temp $\left({ }^{\circ} \mathrm{C}\right)$ & $\begin{array}{l}\text { Amplicons } \\
\text { length } \\
\text { (bp) }\end{array}$ \\
\hline \multirow{8}{*}{$\begin{array}{l}\text { eNOS } \\
\text { (rs1799983) } \\
894 G>T\end{array}$} & Forward outer primer & & \\
\hline & GAGGAGGGCATGAGGCTCAGCCCCAGAA & 63 & \\
\hline & Reverse outer primer & & 277 \\
\hline & GGATCAGCACCCCCTTGCAGGCCCTTCT & 63 & \\
\hline & Forward inner primer (G allele) & & \\
\hline & СCCCTGCTGCTGCAGGCCCCAGATAAG & 65 & 175 \\
\hline & Reverse inner primer ( $T$ allele) & & \\
\hline & CGGGGGGCAGAAGGAAGAGTTCTGGGAGA & 65 & 158 \\
\hline \multirow{8}{*}{$\begin{array}{l}\text { TGF } 11 \\
\text { (rs1800471) } \\
915 \text { C>G }\end{array}$} & Forward outer primer & & \\
\hline & CCTCCCCACCACACCAGCCCTGTTCG CG & 62 & \\
\hline & Reverse outer primer & & 304 \\
\hline & GTACAGGGCGAGCACGGCCTCGGGCAGC & 62 & \\
\hline & Forward inner primer (G allele) & & \\
\hline & GCTGTGGCTACTGGTGCTGACGCCTGGGCG & 66 & 200 \\
\hline & Reverse inner primer (C allele) & & \\
\hline & GCAGGTGGATAGTCCCGCGGCCGCCG & 66 & 160 \\
\hline
\end{tabular}

\section{Validation assay of the genotyping results}

The validation of the genotyping results was done by using the DNA sequencing method. Random DNA samples were taken for sequencing and for this the outer primers both forward and reverse primers were taken applicably to amplify the region of each SNP. The reaction used for the amplification of the specified region was executed in a total reaction mixture of $25 \mu \mathrm{l}$. To verify the genotyping results random samples were selected for sequencing analysis by the Sanger sequencing method.

\section{Statistical analysis}

The statistical analysis was performed by using the SPSS version 21 software for Windows (IBM Analytic, USA). The significance of demographic information among the cases and healthy controls were done by the Chi-square test. The association among the two genetic polymorphisms and their susceptibility to DN was evaluated by the Odds ratio and 95\% confidence interval (CI) under four diverse genetic models which involved the co-dominant model, dominant model, recessive model, and the allelic model. A significant difference was assumed if the two-sided $p$-value $\leq 0.05$. Hardy-Weinberg equilibrium (HWE) was assessed by the $\chi^{2}$ test to determine the distribution of polymorphism among the controls.

\section{Results}

\section{Demographic characteristics of the study population}

The demographic and biochemical parameters of all the study participants included in the case-control study are presented in Table 2. This table displays the clinical and anthropometric levels of all the three different groups of participants involved in the study. A whole of 420 participants were involved in the study, out of which there were 197 (47\%) men and 223 (53\%) women with a mean age 55.6 \pm 6.36 and the mean BMI was 24.0 \pm 3.6 . The subjects were divided into three different groups as the T2DM patients with and without DN and control groups each comprising of 140 participants per group. The levels of fasting and postprandial blood glucose, Serum creatinine, LDL, SBP, and DBP were significantly $(p<0.05)$ greater in the T2DM patients with the $\mathrm{DN}$ group in comparison to the controls. Whereas eGFR was observed to be reduced in the T2DM with diabetic nephropathy group than the other two groups $(p<0.05)$.

\section{Genotypic frequency distribution between T2DM with and without DN in eNOS and TGF- $\beta 1$ gene polymorphisms}

No substantial deviations from Hardy-Weinberg equilibrium (HWE) $(p>0.05)$ were found in the genotypic distributions among the variants in either of the study groups. The genotype and allelic frequencies of both rs1799983 
Table 2 Demographic and clinical characteristics of the study subjects

\begin{tabular}{|c|c|c|c|c|}
\hline Characteristics & $\begin{array}{l}\text { T2DM patients with DN } \\
(N=140)\end{array}$ & $\begin{array}{l}\text { T2DM patients without } \\
\text { DN } \\
(N=140)\end{array}$ & $\begin{array}{l}\text { Control } \\
(N=140)\end{array}$ & $P$ value \\
\hline Gender (Male:Female) & 75:65 & $62: 78$ & $60: 80$ & 0.91 \\
\hline Age (years) & $56.2 \pm 5.7$ & $55.5 \pm 6.6$ & $55.1 \pm 6.8$ & 0.44 \\
\hline $\operatorname{BMI}\left(\mathrm{kg} / \mathrm{m}^{2}\right)$ & $24.0 \pm 4.1$ & $24.0 \pm 3.4$ & $24.2 \pm 3.5$ & 0.56 \\
\hline \multicolumn{5}{|l|}{ Diabetes duration (years) } \\
\hline $3-5$ years & 38 & 32 & - & \\
\hline $5-10$ years & $34(11.4 \pm 4.0)$ & $46(11 \pm 3.8)$ & - & 0.45 \\
\hline$>10$ years & 68 & 62 & - & \\
\hline Fasting blood glucose (mg/dL) & $156.0 \pm 12.7$ & $151.1 \pm 4.3$ & $87.9 \pm 8.9$ & $<0.001$ \\
\hline Postprandial glucose (mg/dL) & $171.3 \pm 53.3$ & $164.8 \pm 42.7$ & $118.9 \pm 12.3$ & $<0.001$ \\
\hline $\mathrm{HbA1c}(\%)$ & $9.0 \pm 2.2$ & $8.9 \pm 1.9$ & $7.8 \pm 2.0$ & 0.68 \\
\hline Protein-to-creatinine ratio ( mg/g) & $62.8 \pm 5.7$ & $54.3 \pm 2.5$ & $32.4 \pm 1.23$ & $<0.001$ \\
\hline Serum creatinine $(\mathrm{mg} / \mathrm{dL})$ & $2.80 \pm 2.7$ & $0.9 \pm 0.24$ & $0.8 \pm 0.15$ & $<0.001$ \\
\hline $\mathrm{HDL}(\mathrm{mg} / \mathrm{dl})$ & $64.1 \pm 15.9$ & $61.05 \pm 18.08$ & $49 \pm 15.7$ & 0.08 \\
\hline LDL (mg/dl) & $97.2 \pm 29.2$ & $95.1 \pm 30.3$ & $93.6 \pm 31.0$ & 0.96 \\
\hline eGFR (ml/min) & $55 \pm 13.1$ & $101.1 \pm 12.3$ & $130.8 \pm 16.0$ & $<0.001$ \\
\hline $\mathrm{SBP}(\mathrm{mmHg})$ & $145.7 \pm 5.5$ & $135.08 \pm 7.1$ & $113 \pm 7.3$ & $<0.001$ \\
\hline $\mathrm{DBP}(\mathrm{mmHg})$ & $104.8 \pm 4.9$ & $90.3 \pm 5.2$ & $75.2 \pm 5.4$ & $<0.001$ \\
\hline
\end{tabular}

Data are in mean \pm SD

$B M I$ body mass index, HbA1c glycosylated haemoglobin, HDL high-density lipoprotein, $L D L$ low-density lipoprotein, eGFR estimated glomerular filtration rate, SBP systolic blood pressure, DBP diastolic blood pressure

$p<0.05$ indicates statistical significance

Table 3 Association of eNOS and TGF- $\beta 1$ gene polymorphisms in T2DM patients with and without DN

\begin{tabular}{|c|c|c|c|c|c|}
\hline Gene(rsID) & Models & $\begin{array}{l}\text { T2DM patients } \\
\text { with DN } \\
N=140\end{array}$ & $\begin{array}{l}\text { T2DM patients } \\
\text { without DN } \\
N=140\end{array}$ & Odds ratio $(95 \% \mathrm{Cl})$ & $P$ value \\
\hline & Co dominant model & & & & \\
\hline & GG & 73 & 80 & 1.00 & - \\
\hline & GT & 24 & 32 & $0.69(0.38-1.26)$ & 0.23 \\
\hline & $\mathrm{TT}$ & 45 & 28 & $1.89(1.09-3.26)$ & $0.02^{*}$ \\
\hline \multirow{9}{*}{$\begin{array}{l}\text { eNOS } \\
\text { (rs1799983) }\end{array}$} & Dominant model-GT+TT vs GG & 78 & 65 & $1.45(0.90-2.32)$ & 0.12 \\
\hline & Recessive model-TT vs GG + GT & 87 & 60 & $2.18(1.35-3.53)$ & $0.001^{*}$ \\
\hline & Allelic model & & & & \\
\hline & Allele G & 177 & 212 & 1.00 & - \\
\hline & Allele T & 103 & 68 & $0.55(0.39-0.79)$ & $0.001^{*}$ \\
\hline & Co dominant model & & & & \\
\hline & GG & 85 & 82 & 1.00 & - \\
\hline & GC & 29 & 30 & $0.95(0.53-1.70)$ & 0.87 \\
\hline & CC & 26 & 28 & $0.91(0.50-1.65)$ & 0.76 \\
\hline \multirow{5}{*}{$\begin{array}{l}\text { TGF- } \beta 1 \\
\text { (rs1800471) }\end{array}$} & Dominant model-GC + CC vs GG & 57 & 62 & $0.86(0.53-1.38)$ & 0.54 \\
\hline & Recessive model-CC vs GG + GC & 68 & 73 & $0.87(0.54-1.38)$ & 0.56 \\
\hline & Allelic model & & & & \\
\hline & Allele G & 180 & 176 & 1.00 & - \\
\hline & Allele C & 100 & 104 & $1.06(0.75-1.50)$ & 0.72 \\
\hline
\end{tabular}

eNOS endothelial nitric oxide, TGF- $\beta 1$ transforming growth factor ${ }^{*} p<0.05$ 
and rs1800471 polymorphisms were evaluated by using odds ratio and (95\%CIs) confidence intervals and the $p$-value as shown in Table 3. The abovementioned table displayed the positive association of rs1799983 polymorphism and a negative association of rs1800471 polymorphism in the comparison between diabetic patients with and without nephropathy.

The analysis of rs 1799983 polymorphism demonstrated a positive association of T2DM with and without DN. In the current study, T2DM subjects with DN and TT genotype have a 2.40 increased risk to develop diabetic nephropathy. The TT vs GG + GT genotype had an odds ratio (OR) and a 95\% confidence interval of $0.34(0.15-$ $0.74)$ under a recessive model $(p=0.007)$. The wild type $\mathrm{T}$ allele frequency also presented a significant association among T2DM patients with and without $\mathrm{DN}$, with an odds ratio of $1.81(1.19-2.75), p=0.004$. Whereas the analysis of rs1800471 polymorphism showed no significant dissimilarities among the T2DM patients with and without $\mathrm{DN}$ in the dominant and recessive models.

\section{Genotypic frequency distribution between T2DM with DN and Controls in eNOS and TGF- $\beta 1$ gene polymorphisms}

The genotypic and allelic frequencies of both rs1799983 and rs1800471 polymorphisms in T2DM patients with
DN and controls were performed as shown in Table 4. The abovementioned table displayed the positive association of rs1799983 polymorphism and a negative association of rs1800471 polymorphism in the comparison between diabetic patients with diabetic nephropathy and healthy controls. The frequency distribution in the control group was in accordance with the HWE $(p>0.05)$. Further, the genotypic model of rs1799983 showed $\mathrm{OR}=3.31(1.46-4.10)$ and $p$-value $=0.004$ whereas the allelic model showed $\mathrm{OR}=2.01(1.32-3.08)$ $p$-value $=0.001$. Likewise, the dominant and recessive models indicated $\mathrm{OR}=1.45(0.84-2.49) \quad p$-value $=0.17$ and $\mathrm{OR}=0.12(0.04-0.38) \quad p$-value $=0.0002$, respectively. The genotypic, allelic, and dominant models of rs1799983 polymorphism showed a strong positive association in T2DM patients with DN in comparison with the control however, the dominant model showed a negative association in the diabetic patients with DN as compared with control with $p \geq 0.05$. Also, the analysis of rs 1800471 polymorphism showed a negative association in the diabetic patients with $\mathrm{DN}$ and control by showing a $p$-value $\geq 0.05$ among the genotypic, allelic, dominant, and recessive genetic models, respectively.

Table 4 Association of eNOS and TGF- $\beta 1$ gene polymorphisms in T2DM patients with DN and controls

\begin{tabular}{|c|c|c|c|c|c|}
\hline Gene(rsID) & Models & $\begin{array}{l}\text { T2DM patients with } \\
\text { DN } \\
N=140\end{array}$ & $\begin{array}{l}\text { Controls } \\
N=140\end{array}$ & Odds ratio $(95 \% \mathrm{Cl})$ & $P$ value \\
\hline & Co dominant model & & & & \\
\hline & GG & 71 & 82 & 1.00 & - \\
\hline & GT & 36 & 42 & $0.80(0.47-1.36)$ & 0.42 \\
\hline & $\mathrm{TT}$ & 33 & 16 & $2.39(1.24-4.58)$ & $0.008^{*}$ \\
\hline \multirow{9}{*}{$\begin{array}{l}\text { eNOS } \\
\text { (rs1799983) }\end{array}$} & Dominant model- GT+TT vs GG & 76 & 64 & $1.41(0.88-2.25)$ & 0.15 \\
\hline & Recessive model-TT vs GG + GT & 86 & 67 & $1.73(1.07-2.79)$ & $0.02^{*}$ \\
\hline & Allelic model & & & & \\
\hline & Allele G & 177 & 225 & 1.00 & - \\
\hline & Allele T & 103 & 55 & $0.42(0.28-0.61)$ & $0.0001^{*}$ \\
\hline & Co dominant model & & & & \\
\hline & GG & 85 & 79 & 1.00 & - \\
\hline & GC & 29 & 32 & $0.88(0.49-1.55)$ & 0.66 \\
\hline & CC & 26 & 29 & $0.87(0.48-1.57)$ & 0.65 \\
\hline \multirow{4}{*}{$\begin{array}{l}\text { TGF- } \beta 1 \\
\text { (rs1800471) }\end{array}$} & Dominant model-GC + CC vs GG & 76 & 83 & $0.81(0.50-1.30)$ & 0.39 \\
\hline & $\begin{array}{l}\text { Recessive model-CC vs GG + GC } \\
\text { Allelic model }\end{array}$ & 62 & 74 & $0.70(0.44-1.13)$ & 0.15 \\
\hline & Allele G & 180 & 171 & 1.00 & - \\
\hline & Allele C & 100 & 109 & $1.14(0.81-1.61)$ & 0.43 \\
\hline
\end{tabular}

eNOS endothelial nitric oxide, TGF- $\beta 1$ transforming growth factor ${ }^{*} p<0.05$ 


\section{Genotypic frequency distribution between T2DM patients without DN and controls in eNOS and TGF- $\beta 1$ gene polymorphisms}

The genotypic and allelic frequencies of both rs1799983 and rs1800471 polymorphisms in T2DM patients without DN and controls were performed as shown in Table 5. The abovementioned table displayed the positive association of rs1799983 polymorphism and a negative association of rs1800471 polymorphism in the comparison between diabetic patients without diabetic nephropathy and healthy controls.

The frequency distribution in the control group was in accordance with the HWE $(p>0.05)$. Further, the genotypic model of rs1799983 showed a negative association in the diabetic patients without DN when compared with the control group exhibiting a $p$-value of $\geq 0.05$ in all the models such as allelic, dominant, and recessive. Furthermore, the analysis of rs1800471 polymorphism also showed a negative association in T2DM patients without $\mathrm{DN}$ and control by showing a $p$-value of $\geq 0.05$ among all the genetic models. The Table 6 shows a positive association of rs1799983 polymorphism, systolic and diastolic blood pressure and diabetic duration which specified an increased risk of DN in diabetic patients. Whereas, rs1800471 did not show any significant effects. The Table indicates positive association of diabetes duration
Table 6 Logistic regression analysis for the association among diabetic nephropaathy, genetic polymorphisms and potential risk factors in type 2 diabetes patients

\begin{tabular}{llll}
\hline Variables & Odds ratio & $\mathbf{9 5 \%} \mathbf{C l}$ & $\boldsymbol{P}$ value \\
\hline Age & 1.03 & $0.43-1.08$ & 0.94 \\
Diabetes duration (years) & 1.32 & $0.67-2.26$ & $0.01^{*}$ \\
BMI & 0.76 & $0.23-0.98$ & 0.57 \\
FBG (mg/dl) & 1.26 & $0.63-2.02$ & 0.35 \\
PPG(mg/dl) & 1.22 & $0.94-3.12$ & 0.06 \\
Smoking & 0.97 & $0.35-1.23$ & 0.21 \\
Systolic blood pressure & 1.45 & $0.87-2.85$ & $0.03^{*}$ \\
Diastolic blood pressure & 1.20 & $0.76-1.53$ & $0.01^{*}$ \\
Serum creatinine(mg/dl) & 0.88 & $0.58-1.44$ & 0.26 \\
Protein-to-creatinine ratio(mg/g) & 1.51 & $0.61-2.00$ & 0.08 \\
eGFR(ml/min) & 1.27 & $0.82-2.61$ & 0.10 \\
rs1799983 genotype(GT) & 1.78 & $1.18-3.24$ & $0.01^{*}$ \\
rs1800471 genotype (GC) & 0.40 & $0.34-1.15$ & 0.12 \\
\hline
\end{tabular}

$B M I$ body mass index, $F B G$ fasting blood glucose, $P P G$ postprandial blood glucose, eGFR estimated glomerular filtration rate, $O R$ odds ratio, $\mathrm{Cl}$ confidence interval

$(p<0.01)$, systolic blood pressure $(p<0.03)$, diastolic blood pressure $(p<0.01)$, and rs1799983 demonstrated a $p<0.01$ which showed an increased risk of DN in diabetic patients.

Table 5 Association of eNOS and TGF- $\beta 1$ gene polymorphisms in T2DM patients without DN and Controls

\begin{tabular}{|c|c|c|c|c|c|}
\hline Gene(rsID) & Models & $\begin{array}{l}\text { T2DM patients } \\
\text { without DN } \\
N=140\end{array}$ & $\begin{array}{l}\text { Controls } \\
N=140\end{array}$ & Odds ratio $(95 \% \mathrm{Cl})$ & $P$ value \\
\hline & Co dominant model & & & & \\
\hline & GG & 80 & 82 & 1.00 & - \\
\hline & GT & 38 & 42 & $0.86(0.51-1.46)$ & 0.59 \\
\hline & $\mathrm{TT}$ & 22 & 16 & $1.44(0.72-2.88)$ & 0.29 \\
\hline \multirow{8}{*}{$\begin{array}{l}\text { eNOS } \\
\text { (rs1799983) }\end{array}$} & Dominant model-GT + TT vs GG & 63 & 59 & $1.12(0.70-1.80)$ & 0.62 \\
\hline & Allelic model & & & & \\
\hline & Allele G & 212 & 225 & 1.00 & - \\
\hline & Allele T & 68 & 55 & $0.76(0.50-1.13)$ & 0.18 \\
\hline & Co dominant model & & & & \\
\hline & GG & 82 & 79 & 1.00 & - \\
\hline & GC & 30 & 32 & $0.92(0.52-1.61)$ & 0.77 \\
\hline & $\mathrm{CC}$ & 28 & 29 & $0.95(0.53-1.71)$ & 0.88 \\
\hline \multirow{4}{*}{$\begin{array}{l}\text { TGF- } \beta 1 \\
\text { (rs1800471) }\end{array}$} & Dominant model- GC + CC vs GG & 62 & 67 & $0.86(0.54-1.38)$ & 0.54 \\
\hline & $\begin{array}{l}\text { Recessive model-CC vs GG + GC } \\
\text { Allelic model }\end{array}$ & 45 & 57 & $0.68(0.42-1.12)$ & 0.13 \\
\hline & Allele G & 176 & 171 & 1.00 & - \\
\hline & Allele C & 104 & 109 & $1.07(0.76-1.51)$ & 0.66 \\
\hline
\end{tabular}

eNOS endothelial nitric oxide, TGF- $\beta 1$ transforming growth factor ${ }^{*} p<0.05$ 
Table 7 Characteristics and clinical parameters of different eNOS genotypes

\begin{tabular}{llll}
\hline Clinical characteristics & eNOS GG & eNOS TT & P value \\
\hline Age (years) & $55.5 \pm 0.61$ & $55.1 \pm 0.35$ & NS \\
Gender (male/female) & $43 / 64$ & $52 / 89$ & NS \\
BMl (kg/m²) & $25.1 \pm 1.11$ & $24.9 \pm 1.09$ & NS \\
Diabetes duration (years) & $15.3 \pm 0.4$ & $12 \pm 0.1$ & $<0.001$ \\
Fasting blood glucose (mg/dL) & $135.9 \pm 0.66$ & $141.8 \pm 2.60$ & $0.0007^{*}$ \\
Post prandial glucose (mg/dL) & $123.4 \pm 1.48$ & $125.8 \pm 2.16$ & $0.03^{*}$ \\
HbA1c (\%) & $7.6 \pm 2.2$ & $8.6 \pm 1.2$ & $<0.05^{*}$ \\
eGFR (ml/min) & $73.5 \pm 1.38$ & $66.1 \pm 2.1$ & $0.03^{*}$ \\
Protein-to-creatinine ratio (mg/g) & $49.3 \pm 2.4$ & $62.3 \pm 3.2$ & $<0.001^{*}$ \\
Systolic blood pressure (mmHg) & $115 \pm 0.80$ & $125.8 \pm 0.8$ & $<0.001^{*}$ \\
Diastolic blood pressure $(\mathrm{mmHg})$ & $78.7 \pm 1.43$ & $83.0 \pm 4.12$ & $0.01^{*}$ \\
\hline
\end{tabular}

Data are $n$, means \pm SEM

$B M I$ body mass index, HbA1c glycosylated haemoglobin, eNOS endothelial nitric oxide, eGFR estimated glomerular filtration rate, NS non-significant

${ }^{*} p<0.05$

\section{Clinical characteristics of eNOS and TGF- $\beta 1$ genotypes}

Table 7 illustrates the clinical as well as biochemical features of T2DM patients with and without DN in different genotypes of eNOS gene polymorphism. As table indicates a positive association with $p<0.01$ was shown by several parameters like diabetes duration, FBS, PPG, HbA1c, eGFR, PCR, systolic and diastolic blood pressure in association with increased risk of DN in diabetic patients with the presence of TT genotype of rs1799983 polymorphism. A substantial difference was found among the diabetic patients with and without DN which was confirmed by the frequencies of the wildtype GG and heterozygous frequencies. It was observed that despite the factors such as less duration of diabetes, levels of glucose, HbA1c, eGFR, protein creatinine ratio, systolic blood pressure, diastolic blood pressure, the renal function declined more rapidly in the diabetic patients with diabetic nephropathy and the TT heterozygous genotype when compared with the wildtype GG genotype. The frequency of TT genotype was considerably higher in the diabetic patients with $\mathrm{DN}$ in comparison to those patients without DN. However, no significance was found among the other factors such as age, gender, and BMI. Whereas the T2DM patients with DN and TGFB1 (G/C) genotypes, did not show any significance in the clinical as well as the biochemical characteristics (data not shown).

\section{Discussion}

The present study has examined the role of $e N O S$ gene variants and TGF $\beta 1$ variants with the risk of progression of nephropathy in DN patients with type 2 diabetes. The results have shown a strong association between diabetic patients with DN ( $p$ value $<0.05)$ signifying that eNOS variants can be a possible risk factor in the development of diabetic nephropathy in type 2 diabetic patients. Further, no significant results were obtained amongst the TGF $\beta 1$ variants and diabetic nephropathy in the study population. Existing studies have shown that an abnormal $e N O S$ activity produced because of the mutation could be associated with various pathological conditions like hypertension, and atherosclerosis, which may further deteriorate the endovascular injury in diabetic patients. $e N O S$ is likely to enhance the sensitivity of glomerular disease in the metabolic environment of diabetes and propose that this pathway can be convoluted in the renal complications of type 1 as well as type 2 diabetic patients. Moreover, polymorphisms in the eNOS gene expression are proved to be linked with diabetic nephropathy among diabetes patients. The mechanism which is responsible for this probable association is still unknown. Nevertheless, the genetic variants of eNOS are known to be the basis of a defective synthesis of nitric oxide at a low level thereby intensifying the predisposition to glomerular disease and therefore decline the renal function [17]. Hence there is a possibility that the metabolic pathway of diabetes can intricate in the renal complications as well. Our results were supported by the outcomes of a metaanalysis by Varghese et al., as their findings suggested a positive association of rs1799983 polymorphism with a higher risk of diabetic nephropathy [18]. These results are also in agreement with the conclusions of Sahar et al.,Shin Shin et al., and Neugebauer et al., who proved the association of eNOS polymorphism in the advancement of diabetic nephropathy in Korean and Japanese T2DM patients, respectively [19-22]. The results with reference to rs1799983 have shown a strong association of the TT genotype and T allele between DN patients and T2DM with an odds ratio of 1.89 (1.09-3.26) and a $p$ value $=0.02$ signifying that mutant $\mathrm{T}$ allele can be a possible risk factor in the advancement of diabetic nephropathy in type 2 diabetic patients. The study by Mohd et al., 2019 stated a highest odds ratio 2.39 (1.17-4.88) among the other studies, and thereby showed a wide-range of confidence interval which suggested small sample size or other factors leading to probable bias. In contrast with the aforementioned study, even though the present study resulted in a lesser odds ratio and low range of confidence interval but exhibited a significant difference along with a higher heterogeneity towards increased risk.

Mohd et al., have reported the case-control association study, in order to assess the influence of four different oxidative stress-related gene polymorphisms including NOS3 rs1799983 polymorphism as risk factors in the progression of diabetic nephropathy in Malaysian 
diabetic patients [23]. Their findings demonstrated that the T allele of NOS3 gene polymorphism is significantly linked with the development of DN specifically amongst the Chinese and Indian populations included in the study. A recent study by Shoily et al., 2021 have proved the association of rs1799983 polymorphism of NOS3 to have positive link specifically in the populations such as European and Americans. They have demonstrated the role of NOS3 genetic polymorphism in the progression of diabetes and diabetic complications such as diabetic nephropathy, retinopathy etc. [24].

With respect to the TGF $1 \quad(-915 \mathrm{G}>\mathrm{C})$ polymorphism, the present study did not find any significant association in the advancement of diabetic nephropathy. The results with reference to rs 1800471 , the CC genotype have shown an OR and 95\% CI of 0.91 (0.50-1.65) non-significant risk displaying a $p=0.76$ in the T2DM patients with and without DN. These results are in agreement with the findings of El-Sherbini et al., where they found insignificant dissimilarities in the alleles and genotypic frequencies of TGF $\beta 1$ (G915C) polymorphism in Egyptian type 2 diabetic patients [25]. McKnight et al., and Zhang et al., have also indicated the insignificant results of TGF 1 variants with the risk of $\mathrm{DN}$ among the Asian and Caucasian population respectively [26, 27]. Nevertheless, opposing to these results Valladares et al. (2010) have reported a positive association of T869C and G915C polymorphisms of the TGF $\beta 1$ gene with DN. They also stated that lower levels of triglycerides, as well as cholesterol, were noticed in subjects with TT homozygotes for the T869C polymorphism. They reported a highest OR of 4.16 (2.92-5.94) among the other studies, which was also comparatively very high than our study [28]. Another recent meta-analysis study by Mai et al., 2020 has also proved the association of TGF $\beta 1$ polymorphism (rs18000471) in the development of chronic kidney diseases [29].

Such difference between the results is based on the ethnicity of different study populations. These genetic variances will be due to different lifestyles as well as diverse linkage maps. The ethnicity-specific association studies are required to elucidate the population stratification of diabetic nephropathy and related risk factors.

\section{Conclusion}

In conclusion, this case-control study exhibits a significant association of $e N O S$ gene variant (rs1799983) in the development of DN in type 2 diabetic patients. This investigation further reported a non-significant association of the TGF $\beta 1$ gene variant (rs1800471) in the progression of diabetic nephropathy in the studied population. This association study can probably assist in identifying the genotypes of the indicated genes in patients with renal disorders who are at high risk of developing diabetic nephropathy. Though these findings alone will not be sufficiently adequate to get a piece of conclusive evidence primarily because of the small sample size of the studied population. Still, it could be considered as strong evidence with significant information on the influence of the investigated genetic variants on the susceptibility to diabetic nephropathy. Further, it is essential to enlarge the sample size and combine it with other risk factors such as lifestyle changes in order to increase the knowledge on more issues influencing the advancement of diabetic nephropathy.

\section{Abbreviations}

DN: Diabetic nephropathy; T2DM:Type 2 diabetes mellitus; ESRD: End-stage renal disease; eNOS: Endothelial nitric oxide synthase; TGF- $\beta 1$ : Transforming growth factor-beta 1; Tetra-ARMS-PCR: Tetra-primer amplification refractory mutation system PCR; KDOQI: Kidney Disease Outcomes Quality Initiative; HWE: Hardy-Weinberg equilibrium.

\section{Acknowledgements \\ The authors would like to thank Chancellor, Vice-Chancellor, Managing Trustee, Registrar of Chettinad Academy of Research and Education for the consistent support to carry out the study.}

\section{Authors' contributions}

The first author (S.V) carried out the genotyping studies, interpretation of the data and performed statistical analysis and drafted the manuscript. G.K: revised the final draft of the manuscript and approved for further procedures. Both authors read and approved the final manuscript.

\section{Funding}

This research work is not funded.

\section{Availability of data and materials}

The datasets analysed during the current study are available with the corresponding author on reasonable request.

\section{Declarations}

Ethics approval and consent to participate

The current study was approved by the Institution's Ethical Committee of Chettinad Academy of Research and Education on 19 November 2017 with an approval number (IHEC No 366/IHEC/10-17). A written informed consent form was attained from all participants involved in the study.

\section{Consent for publication}

The consent for publication were obtained from all the participants enrolled in the study.

\section{Competing interests}

All the authors state that there is no conflict of interest.

Received: 19 May 2021 Accepted: 27 October 2021

Published online: 12 January 2022

References

1. Gross JL, De Azevedo MJ, Silveiro SP, Canani LH, Caramori ML, Zelmanovitz T (2005) Diabetic nephropathy: diagnosis, prevention, and treatment. Diabetes Care 28(1):164-176

2. Varghese S, Kumar SG (2019) Prevalence of micro albuminuria and diagnostic accuracy of urine dipstick for the screening of diabetic nephropathy in type 2 diabetes patients. Biocatalysis Agric Biotechnol 21:101316 
3. Bowden DW (2002) Genetics of diabetes complications. Curr DiabRep 2(2):191-200

4. Zintzaras E, Papathanasiou AA, Stefanidis I (2009) Endothelial nitric oxide synthase gene polymorphisms and diabetic nephropathy: a HuGE review and meta-analysis. Genet Med 11(10):695-706

5. Zeng Z, Li L, Zhang Z, Li Y, Wei Z, Huang K, He L, Shi Y (2010) A meta-analysis of three polymorphisms in the endothelial nitric oxide synthase gene (NOS3) and their effect on the risk of diabetic nephropathy. Hum Genet 127(4):373-381

6. Chiarelli F, Gaspari S, Marcovecchio ML (2009) Role of growth factors in diabetic kidney disease. Hormone Metabolic Res 41 (8):585-593

7. Rahimi Z, Vaisi-Raygani As, Rahimi Z, Parsian A (2012) Concomitant presence of endothelial nitric oxide 894t and angiotensin li-converting enzyme D alleles are associated with diabetic nephropathy. In: Kurdish A (ed) Population from Western Iran. Nephrology 17(2):175-181

8. Santos KG, Crispim D, Canani LH, Ferrugem PT, Gross JL, Roisenberg I (2011) Association of eNOS gene polymorphisms with renal disease in Caucasians with type 2 diabetes. Diabetes Res Clin Pract 91(3):353-362

9. Braga Gomes K, Fontana Rodrigues K, Fernandes AP. The role of transforming growth factor-beta in diabetic nephropathy. International Journal of Medical Genetics. 2014;2014.

10. Fujii D, Brissenden JE, Derynck R, Francke U (1986) Transforming growth factor $\beta$ gene maps to human chromosome 19 long arm and to mouse chromosome 7. Somat Cell Mol Genet 12(3):281-288

11. Derynck R, Rhee L, Chen EY, Van Tilburg A (1987) Intron-exon structure of the human transforming growth factor-beta precursor gene. Nucleic Acids Res 15(7):3188

12. Wong TY, Poon P, Chow KM, Szeto CC, Cheung MK, Li PK (2003) Association of transforming growth factor-beta (TGF- $\beta$ ) T869C (Leu 10Pro) gene polymorphisms with type 2 diabetic nephropathy in Chinese. Kidney Int 63(5):1831-1835

13. Mittal RD, Manchanda PK (2007) Is low-frequency distribution of TGF- $\beta$ genotype associated with increased risk for end-stage renal disease? DNA Cell Biol 26(3):172-177

14. American Diabetes Association (2015) Standards of medical care in diabetes - 2015 abridged for primary care providers. Clin Diabetes: Publ Am Diabetes Assoc 33(2):97

15. Foundation NK (2012) KDOQI clinical practice guideline for diabetes and CKD: 2012 update. Am J Kidney Dis 60(5):850-886

16. Miller SA, Dykes DD, Polesky HF (1988) A simple salting out procedure for extracting DNA from human nucleated cells. Nucleic Acids Res 16(3):1215

17. Ye S, Dhillon S, Ke X, Collins AR, Day IN (2001) An efficient procedure for genotyping single nucleotide polymorphisms. Nucleic Acids Res 29(17):e88

18. Ahluwalia TS, Ahuja M, Rai TS, Kohli HS, Sud K, Bhansali A, Khullar M (2008) Endothelial nitric oxide synthase gene haplotypes and diabetic nephropathy among Asian Indians. Mol Cell Biochem 314(1-2):9-17

19. Varghese S, Kumar SG (2019) Association between genetic variants of NOS3, TGF- $\beta$ and susceptibility of diabetic nephropathy: a meta-analysis. Meta Gene 21:100573

20. Bessa SS, Hamdy SM (2011) Impact of nitric oxide synthase Glu298Asp polymorphism on the development of end-stage renal disease in type 2 diabetic Egyptian patients. Ren Fail 33(9):878-884

21. Shin YS, Baek SH, Chang KY, Park CW, Yang CW, Jin DC, Kim YS, Chang YS, Bang BK (2004) Relations between eNOS Glu298Asp polymorphism and progression of diabetic nephropathy. Diabetes Res Clin Pract 65(3):257-265

22. Neugebauer S, Baba T, Watanabe T (2000) Association of the nitric oxide synthase gene polymorphism with an increased risk for progression to diabetic nephropathy in type 2 diabetes. Diabetes 49(3):500-503

23. Yahya MJ, Ismail PB, Nordin NB, Akim AB, Binti Md Yusuf WS, Adam NL, Zulkifli NF (2019) CNDP1, NOS3, and MnSOD polymorphisms as risk factors for diabetic nephropathy among type 2 diabetic patients in Malaysia. Journal of nutrition and metabolism. 2019

24. Shoily SS, Ahsan T, Fatema K, Sajib AA (2021) Common genetic variants and pathways in diabetes and associated complications and vulnerability of populations with different ethnic origins. Sci Rep 11(1):1-4

25. El-Sherbini SM, Shahen SM, Mosaad YM, Abdelgawad MS, Talaat RM (2013) Gene polymorphism of transforming growth factor- $\beta 1$ in Egyptian patients with type 2 diabetes and diabetic nephropathy. Acta Biochim Biophys $\operatorname{Sin}$ 45(4):330-338
26. McKnight AJ, Savage DA, Patterson CC, Sadlier D, Maxwell AP (2007) Resequencing of genes for transforming growth factor $\beta 1$ (TGFB1) type 1 and 2 receptors (TGFBR1, TGFBR2), and association analysis of variants with diabetic nephropathy. BMC Med Genet 8(1):5

27. Zhang J, Guan YL, Xiao Y, Zhang XW (2014) A meta-analysis of the association of G915C, G800A, C509T gene polymorphism of transforming growth factor- $\beta 1$ with diabetic nephropathy risk. Ren Fail 36(2):321-326

28. Valladares-Salgado AD, Angeles-Martínez JA, Rosas M, García-Mena JA, Utrera-Barillas DO, Gómez-Díaz RI, Escobedo-De La Peña JO, Parra EJ, Cruz M (2010) Association of polymorphisms within the transforming growth factor- $\beta 1$ gene with diabetic nephropathy and serum cholesterol and triglyceride concentrations. Nephrology 15(6):644-648

29. Mai M, Jiang Y, Wu X, Liu G, Zhu Y, Zhu W (2020) Association of TGF- $\beta 1$, IL-4, and IL-10 polymorphisms with chronic kidney disease susceptibility: a meta-analysis. Front Genet 11:79

\section{Publisher's Note}

Springer Nature remains neutral with regard to jurisdictional claims in published maps and institutional affiliations.

\section{Submit your manuscript to a SpringerOpen ${ }^{\circ}$ journal and benefit from:}

- Convenient online submission

- Rigorous peer review

- Open access: articles freely available online

- High visibility within the field

- Retaining the copyright to your article

Submit your next manuscript at $\boldsymbol{\nabla}$ springeropen.com 